\title{
NEUROPROTECTIVE EFFECT OF CITRULLUS LANATUS SEED EXTRACTS ON CEREBRAL ISCHEMIC REPERFUSION INJURY INDUCED COGNITIVE IMPAIRMENT AND OXIDATIVE STRESS
}

\author{
GIRIJA PASHIKANTI' ${ }^{1}$, MAKULA AJITHA ${ }^{2}$, GOVERDHAN PUCHCHAKAYALA ${ }^{*}$
}

${ }^{1}$ Centre for Neurodegenerative Disease and Aging Research Department of Pharmacology, Vaagdevi College of Pharmacy, Ramnagar, Hanamkonda, Warangal 506001, India, ${ }^{2}$ Centre for Pharmaceutical Sciences, JNTU, Kukatpally, Hyderabad 500085, Telangana, India Email: govku@yahoo.co.in

Received: 08 Mar 2019 Revised and Accepted: 23 Apr 2019

\section{ABSTRACT}

Objective: Oxidative stress appears to be an early event involved in the pathogenesis of Alzheimer's disease (AD). The present study was designed to investigate the neuroprotective effects of citrullus lanatus on bilateral common carotid artery occlusion (BCCA0) induced cognitive impairment and oxidative stress in Wistar albino rats.

\begin{abstract}
Methods: Cognitive impairment and oxidative stress were induced by BCCAO for 30 min, followed by $7 \mathrm{~d}$ reperfusion of male wistar rats. Morris water maze and rectangular maze performance tests and locomotor activity were used to assess memory performance tasks. To study the activity, rats weighing 250-300g were pre-treated with successive extracts of n-hexane fraction (HF), ethyl acetate fraction (EAF), ethanol fraction (EF) and aqueous fraction (AF) of $400 \mathrm{mg} / \mathrm{kg}, 200 \mathrm{mg} / \mathrm{kg}$, p. o of each for $10 \mathrm{~d}$ and the treatment was continued for another $7 \mathrm{~d}$ after cerebral ischemia. Various biochemical parameters like lipid peroxidation, Catalase, DPPH and AchE were also estimated in the brain after the treatment.
\end{abstract}

Results: There was significantly increased oxidative stress and cholinesterase activity with cognitive decline in the hippocampus in rats of BCCAO group as compared to sham-operated $(\mathrm{p}<0.05)$. The animals treated with Donepezil, HF and EF prevented the biochemical changes significantly $(\mathrm{p}<0.001)$ and there was significant $(\mathrm{p}<0.001)$ improvement in cognitive parameters compared to BCCAO treated rats.

Conclusion: Thus present study indicates the neuroprotective effect of citrulus lanatus seed extract (HF and EF) against BCCAO induced cognitive impairment and associative oxidative damage.

Keywords: Antioxidant, Bilateral common carotid artery occlusion, Citrullus lanatus, Cognitive impairment, Oxidative stress

(C) 2019 The Authors. Published by Innovare Academic Sciences Pvt Ltd. This is an open-access article under the CC BY license (http://creativecommons.org/licenses/by/4.0/) DOI: http://dx.doi.org/10.22159/ijpps.2019v11i6.32963

\section{INTRODUCTION}

Alzheimer's disease (AD) is a one of neurodegenerative disorder, it is associated with brain infarction. The characteristic feature of the disease is a cholinergic neuronal loss in the hippocampus and frontal cortex and is considered to emphasize the cognitive deficit and short term memory loss which occur AD. The neuropathological aspect of $\mathrm{AD}$ includes deposits of extracellular amyloid plaques $(A \beta)$ and intraneuronal neurofibrillary tangles [1]. The cause of this disorder is multifactorial and oxidative pressure has been reported to play a foremost role in the onset and development of AD. In view of the mechanistic aspects, it has been predicted that $\beta$-amyloid aggregates synergistically produce oxidative injury by free radical generation [2]. The global cerebral hypoperfusion with bilateral common carotid artery occlusion (BCCAO) induced cognitive impairment is a well-known model, which may induce BBB disruption, neuronal injury in the cortex and hippocampus, cause infarctions in the striatum of unstable sizes and elevated inflammatory responses since cognitive impairment is central in dementia [3]. This causes the death of neurons and related behavioral deficits including sensorimotor abnormality, spatial orientation disorder, and learning-memory impairments.

Phytopharmaceuticals are gaining significance as current medicine as well as the conventional arrangement of medicine with their therapeutic potential. Novel antioxidants may suggest a useful and protective means of strengthening the body's safety against free radicals and thus provide defense towards neurodegenerative problems. A variety of natural antioxidants like curcumin, rosmarinic acid, huperzine A have been shown to have a neuroprotective effect against neurodegeneration [4-6]. The antioxidants can prevent the oxidation process by interfering with free radicals, chelating free catalytic metals and also by acting as oxygen scavengers. Recent 'studies have revealed that the antioxidant mechanisms of plants could be associated with defense against oxidative stress and various human diseases like cancer, atherosclerosis and the aging process $[7,8]$.

Citrullus lanatus (CL) belongs to the family Cucurbitaceae is a medicinal plant widely used conventionally in the management of a variety of disorders in the world. It has been reported to have various pharmacological effects like anthelmintic, anticancer, antibacterial, demulcent and diuretic etc. Additionally, a literature review reveals the uses CL fruit and have various biological activities including anti-oxidants. But seeds are not in generally given importance, even though its seed consists of various phytochemical components like alkaloids, flavonoids, tannins, amino acids, carbohydrates, cardioglycosides, terpenoids, steroids, carotenoids, oils and fats $[9,10]$. Therefore, the present study was designed to investigate the possible In vivo neuroprotective effects of various seed extracts of CL against BCCAO induced cognitive impairment and associated oxidative damage in rats.

\section{MATERIALS AND METHODS}

\section{Chemicals and drugs}

Donapezil, Thiopentone sodium, Hydrogen peroxide, povidone-iodine powder, 5\% w/w (Sri medical and surgical) ethanol, ethyl acetate, nhexane (Venkateshwara agencies) Acetylthiocholine iodide (Sigma Aldrich), Perchloric acid Formalin 10\% (Finar Chemicals), DTNB (5,5dithiobis (2-nitrobenzoic acid) reagent, DPPH (1,1-diphenyl-2picrylhydrazyl) radical reagent (Sigma Aldrich).

\section{Plant material}

The fresh watermelons were collected from the local market of Warangal district, Telangana state, India. The seeds were separated from fruit and shade dried. The collected samples were 
authenticated morphologically (Voucher specimen no. ENM/SU 0019022) by Dr. E. Narasimha Murthy, Department of botany, Satavahana University, Karimnagar-505002, Telangana state, India.

\section{Extraction and fractionation method}

The dried seeds of CL were powdered in a blender. This fine powder was extracted in a soxhlet apparatus with ethanol for about $36 \mathrm{~h}$. The ethanolic extract was cooled, filtered. The filtrate was concentrated by using a rotary evaporator under reduced pressure till the concentrated mass was obtained.

The concentrated ethanol extracts were further subjected to partial fractionation with solvents of increasing polarity viz. Hexane: Ethyl acetate: ethanol: water. Ethanol extracts were dispersed in the nonpolar solvent, Hexane. Hexane dissolved part, which is called hexane fraction (HF), it was filtered and concentrated by evaporating the solvent under reduced pressure. The remainder thus obtained was fractionated subsequently with medium polar solvents such as ethyl acetate (EAF) and finally with a polar solvent, water (AF). The extracts were analysed by means of thin layer chromatography.

\section{Experimental animals}

Young male Wistar rats $(200-250 \mathrm{~g})$ procured from mahaveera enterprises, medchal district-98 were used. Animals were adjusted to laboratory conditions at room temperature prior to experimentation. All the experiments were carried out between 9.00 $\mathrm{AM}$ and 3.00 PM. All animals underwent surgery; they were kept in plastic cages with soft bedding under standard conditions of a 12- hour light/dark cycle with food and water ad libitum. The animal experiments were designed as per CPCSEA guideline and protocol of the experiments after the authorization of the Institutional Animal Ethical Committee (IAEC), Vaagdevi College of Pharmacy, Warangal (A. P) and India (1047/PO/Re/S/07/CPCSEA, dated: 21/10/2017).

\section{Acute toxicity studies}

The acute toxicity of HF, EAF, EF and AF extracts of CL was determined as per the OECD guideline no, 423 (acute toxic class method). It was observed that these seed extracts were not fatal to the rats even at the $2000 \mathrm{mg} / \mathrm{kg}$ doses. Hence, $1 / 5^{\text {th }}(400 \mathrm{mg} / \mathrm{kg})$ and $1 / 10^{\text {th }}(200 \mathrm{mg} / \mathrm{kg})$ of these doses were selected for further studies [11].

\section{Groups and treatment}

The Wistar Albino rats (66) of 250-300 gm weight were randomly divided into 11 groups of 6 rats each. Vehicle and test substances of $\mathrm{HF}, \mathrm{EAF}, \mathrm{EF}$ and AF successive extracts $(400,200 \mathrm{mg} / \mathrm{kg}$ of each) of CL were prepared freshly and given (p. o.) once daily for 10 consecutive days prior to the cerebral ischemia. On day 11, $60 \mathrm{~min}$ after the last dose, all the groups received BCCAO for $30 \mathrm{~min}$ followed by reperfusion for $7 \mathrm{~d}$. From the second (13) day after induction, the animals continued with the test substances for other weekdays, then the animals were assessed for behavioral parameters. After all behavioral assessments, the brains of different groups were removed and assessed for biochemical parameters and histopathological evaluation [12]. The detailed treatment schedule is as in table 1 .

Table 1: Experimental design

\begin{tabular}{ll}
\hline Group number & Treatment \\
\hline I & Sham-operated; $0.1 \%$ of CMC in normal saline $(10 \mathrm{ml} / \mathrm{kg})$ \\
II & BCCAO; $0.1 \%$ of CMC in normal saline $(10 \mathrm{ml} / \mathrm{kg})$ \\
III & BCCAO+received Donepezil $(5 \mathrm{mg} / \mathrm{kg})$ oral \\
IV & BCCAO+HF $(400 \mathrm{mg} / \mathrm{kg})$ orally \\
V & BCCAO+HF $(200 \mathrm{mg} / \mathrm{kg})$ orally \\
VI & BCCAO+EAF $(400 \mathrm{mg} / \mathrm{kg})$ orally \\
VII & BCCAO+EAF $(200 \mathrm{mg} / \mathrm{kg})$ orally \\
VIII & BCCAO+EF $(400 \mathrm{mg} / \mathrm{kg})$ orally \\
IX & BCCAO+EF $(200 \mathrm{mg} / \mathrm{kg})$ orally \\
X & BCCAO+AF $(400 \mathrm{mg} / \mathrm{kg})$ orally \\
XI & BCCAO+AF $(200 \mathrm{mg} / \mathrm{kg})$ orally \\
\hline
\end{tabular}

\section{Drug administration}

Donepezil $(5 \mathrm{mg} / \mathrm{kg}$ ), the HF, EAF, EF and AF (dissolved in $0.1 \%$ CMC) of CL were administered at a dose of 400 and $200 \mathrm{mg} / \mathrm{kg}$ oral. Rats in the sham group and BCCAO group administered solely with an equal amount of normal saline. All drugs were prepared freshly every day. Doses were given according to the respective rat weights.

\section{Induction of cerebral ischemia}

BCCAO was used to trigger global cerebral ischemia. Rats were sedated with thiopentone sodium at a dose of $50 \mathrm{mg} / \mathrm{kg}$, (i. p). A midline opening was made between the neck and sternum and the trachea was exposed. Then both the left and right common carotid arteries were carefully separated. Cerebral ischemia was induced by clamping both of the arteries with two microaneurysmal clips (bulldog clamps). The reperfusion of blood through the carotid arteries allowed after $30 \mathrm{~min}$ of cerebral ischemia by removing both the clips. Sham-operated rats underwent the same surgical procedure without artery occlusion. During the surgery, the body temperature was monitored with a temperature probe and maintained at $37.0-37.5^{\circ} \mathrm{C}$ using a heating pad $[13,14]$.

\section{Behavioural assessments}

All the animals were trained for $10 \mathrm{~d}$ before BCCAO and drug administration.

\section{Spatial navigation task}

The acquisition and retention of a spatial navigation task were assessed by using morris water maze [15]. Rats were trained to swim toward a visible platform in a circular pool $120 \mathrm{~cm}$ in diameter and $60 \mathrm{~cm}$ in height) located in a test room. In principle, rats can escape from swimming by climbing onto the platform and over time the rats have apparently learned the spatial location of the platform from any starting position at the circumference of the pool. Thus the platform offers no local signal to guide the escape behavior of the rats. The pool was filled with water $(28 \pm 2$ Q $)$ to a height of $40 \mathrm{~cm}$, a movable circular platform $(9$ $\mathrm{cm}$ diameter), was placed in a pool $2 \mathrm{~cm}$ above the water level during the acquisition phase. Similarly, for the maze retention phase, the platform was placed in the pool $2 \mathrm{~cm}$ below the water level. The water was made opaque with a nontoxic dye. Four equally spaced locations around the edge of the pool $\left(Q_{1}, Q_{2}, Q_{3}\right.$, and $\left.Q_{4}\right)$ were used as starting points and this divided the pool into four equal quadrants.

\section{Maze acquisition phase (training)}

From the second day after induction, the animals received a training session consisting of 4 trials on day 12. In all 4 trials, the starting position was different. A trial began by releasing the animal into the maze facing towards the wall of the pool. The latency to find the escape platform was recorded to a maximum of 90 seconds. If the rat did not escape onto the platform within this time, it was guided to the platform and was allowed to remain there for 20 seconds. The time taken by the rat to reach the platform was taken as the initial acquisition latency (IAL).

\section{Maze retention phase (testing for retention of the learned task)}

Following $24 \mathrm{~h}$ (day 13) and $8 \mathrm{~d}$ (day 21) after IAL, the rat was released randomly from one of the edges facing the wall of the pool. The time is taken to find the hidden platform was recorded and termed as first 
retention latency (1st RL) and second retention latency (2nd RL) on day 13 and day 21after cerebral ischemia, respectively.

\section{Assessment of gross behavioral activity}

The gross behavioral activity was observed on days 1, 7 before induction and 13, 21 after induction. Animal was placed in a square closed arena equipped with infrared light-sensitive photocells using digital actophotometer, it consists of photoelectric cells, and they are connected with a counter in the circuit. The animals were observed for a period of 5 $\min$ and the values were expressed as counts/5 $\min [16,17]$.

\section{Rectangular maze test}

This test was used to evaluate the learning ability. The maze consists of a fully enclosed rectangular box with an entry and a reward chamber added at opposite ends. The box is partitioned like twisting corridor leading into blind passages from the entry to the reward chamber with wooden slats. From the second day after induction the animals received a training session consisting of 4 trials on day 12 . In each trial the rat was placed in the entry chamber and the timer was activated as soon as the rat leaves the chamber. The time taken by the animal to reach the reward chamber from the entry chamber was recorded as the initial transfer latency (ITL). The animal was allowed to explore the maze for 20 seconds after recording the ITL and then returned to the home cage. If the animal did not enter the reward chamber within 90 seconds, it was guided on the back to reach the reward chamber and the ITL was given as 90 seconds. Retention of memory was assessed by placing the rat in an entry chamber and the retention latency was noted on day 13 and day 21 of ITL and was termed as the first retention transfer latency (1st RTL) and second retention transfer latency (2nd RTL) respectively. Lower scores of the assessment indicate efficient learning while higher scores indicate poor learning in animals $[18,19]$.

\section{Dissection and homogenization}

On day 21 after behavioral assessments, animals were sacrificed by decapitation prior to deep anesthesia. The brains were removed, forebrain was dissected out, and cerebellum was discarded. Hippocampus dissected out from the brain and it was put on ice and rinsed with ice-cold isotonic saline. A $(10 \% \mathrm{w} / \mathrm{v})$ homogenate was prepared with 10 times ice cold $0.1 \mathrm{M}$ phosphate buffer $(p \mathrm{H}$ 7.4). Now the obtained homogenate was centrifuged at 3000rpm for 15 $\mathrm{min}$ and aliquots of supernatant were separated and used for biochemical estimation.

\section{Biochemical tests}

\section{Measurement of lipid peroxidation}

The extent of lipid peroxidation in the brain was determined as described by Wills [20]. The amount of malondialdehyde (MDA) was measured by reaction with thiobarbituric acid at $532 \mathrm{~nm}$ using a spectrophotometer. The values were calculated using the molar extinction coefficient of chromophore $\left(1.56 \times 105(\mathrm{~mol} / \mathrm{l})^{-1} \mathrm{~cm}^{-1}\right)$.

\section{Catalase activity}

Catalase activity was assessed by the method of Luck [21], wherein the breakdown of hydrogen peroxide is measured. Briefly, the assay mixture consisted of $3 \mathrm{ml}$ of $\mathrm{H}_{2} \mathrm{O}_{2}$ phosphate buffer and $0.05 \mathrm{ml}$ of the supernatant of the tissue homogenate. The change in absorbance was recorded for $2 \mathrm{~min}$ at the 30 -second interval at $240 \mathrm{~nm}$ using a spectrophotometer. The results were expressed as micromoles of H2O2 decomposed per minute per mg protein.

\section{DPPH radical scavenging assay}

The free radical scavenging activity of the test drug was measured in vitro by 1, 1-diphenyl-2-picrylhydrazyl (DPPH) assay [22]. In this, measurement is made from the bleaching of a purple coloured methanol solution of DPPH. To the $1000 \mathrm{~L}$ of diverse concentration of the homogenate, $4 \mathrm{ml}$ of $0.004 \%$ methanolic solution of DPPH was added. After 30 min incubation in dark, absorbance was read at 517 $\mathrm{nm}$. Inhibition of free radical by DPPH in percentage was calculated in the following way:

$$
\text { Percentage } \approx(\text { Ablank }- \text { Asample / Ablank }) \times 100
$$

Ablank: absorbance of control reaction. Asample: absorbance of test sample. Values of inhibition were calculated

\section{Acetylcholinesterase estimation}

Acetylcholinesterase (AChE) is a marker of extensive loss of cholinergic neurons in the forebrain. The AChE activity was assessed by Ellman method [23]. The change in absorbance was measured for $2 \mathrm{~min}$ at the 30-second interval at $412 \mathrm{~nm}$ using a spectrophotometer. Results were expressed as micromoles of acetylthiocholine iodide hydrolyzed per minute per mg protein.

\section{Statistical analysis}

Results were expressed in mean \pm SD. The significance of the difference in means between disease control and test drug-treated animals for different parameters was evaluated by using One-way Analysis of Variance (ANOVA) followed by multiple comparisons Dunnett's test. Data were measured statistically, significant at $\mathrm{p}<0.05$ and highly significant at $\mathrm{p}<0.01$. Statistical analysis was executed using GraphPad Prism 7 statistical software.

\section{RESULTS}

\section{Behavioral alteration in rats}

\section{Effect of CL on morris water maze}

Sham-operated, donapezil ( $5 \mathrm{mg} / \mathrm{kg}, \mathrm{PO}$ ) and CL various extract (HF, $\mathrm{EAF}, \mathrm{EF}$ and $\mathrm{AF}$ of 400 and $200 \mathrm{mg} / \mathrm{kg}$, PO) groups of animals quickly learned to swim directly to the platform in the morris water maze on day 12. BCCAO treated rats showed an initial increase in escape latency, which declined with continued training during the acquisition of a spatial navigation task on day 12 . There was a significant difference in the mean IAL of BCCAO treated group compared to the sham-operated group on day 12 indicating BCCAO induced impaired acquisition of spatial navigation task $(\mathrm{P}<0.05)$. In contrast, CL various extract (HF, EAF, EF, and AF of 400 and 200 $\mathrm{mg} / \mathrm{kg}$, PO) treatments after cerebral ischemia significantly decreased the IAL to reach the platform in the pretrained rats as compared to BCCAO treated rats on day 12 (fig. 1). Following training, the mean retention latencies ( $1^{\text {st }}$ and $\left.2^{\text {nd }} \mathrm{RL}\right)$ to escape onto the hidden platform were significantly decreased in sham-operated, donapezil $(5 \mathrm{mg} / \mathrm{kg}, \mathrm{PO})$ and CL various extracts (HF, EAF, EF and $\mathrm{AF}$ of 400 and $200 \mathrm{mg} / \mathrm{kg}$, PO) group rats on days 13 and 21, as compared to IAL on day 12 after induction. On the contrary, the performance in the BCCAO treated rats was changed after initial training in the water maze on days 13 and 21 , with the significant increase in mean retention latencies compared to IAL on day 12 . The results suggest that BCCAO caused significant cognitive impairment. But the order of mean retention latencies compared to IAL on day 13 was $\mathrm{HF}>\mathrm{EF}>\mathrm{EAF}>\mathrm{AF}$. However, chronic $\mathrm{CL}$ extracts of $\mathrm{HF}$ and $\mathrm{EF}$ starting before induction administration showed a significant $\left(\mathrm{P}<0.01\right.$ and $\mathrm{P}<0.05$ respectively) decline in the $1^{\text {st }}$ and $2^{\text {nd }} \mathrm{RL}$, which indicates improved the retention performance of the spatial navigation task in both groups in a concentration-dependent manner as compared to BCCAO treated rats.

\section{Effect of CL on the rectangular maze}

In the present experiment, mean ITL on day 12 for each rat was relatively stable and showed no significant variation among different groups. All the rats entered the reward chamber within 90 seconds. Following training, Sham-operated, donapezil $(5 \mathrm{mg} / \mathrm{kg}, \mathrm{PO})$ and CL various extracts (HF, EAF, EF and AF of 400 and $200 \mathrm{mg} / \mathrm{kg}$, PO) rats entered the reward chamber quickly as compared to BCCAO treated rats. Mean retention transfer latencies ( $1^{\text {st }} \mathrm{RTL}$ and $\left.2^{\text {nd }} \mathrm{RTL}\right)$ to enter the reward chamber on days 13 and 21 were shorter as compared to ITL on day 12 of each group, respectively. In contrast, BCCAO treated rats performed poorly throughout the experiment and did not show any change in the mean retention transfer latencies on days 13 and 21 as compared to pretraining latency on day 12 , demonstrating that BCCAO induced marked memory impairment. Chronic administration of CL various extracts (HF, EAF, EF and AF of 400 and $200 \mathrm{mg} / \mathrm{kg}, \mathrm{PO}$ ) beginning prior to cerebral ischemia significantly decreased the mean retention latencies on days 13 and 21 after 
cerebral ischemia. The mean transfer latencies of CL extracts of HF and EF were significantly decreased in a concentration-dependent manner on days 13 and $21(\mathrm{P}<0.01$ and $\mathrm{P}<0.05$ respectively) than $\mathrm{CL}$ of $\mathrm{EAF}$ and AF extracts when compared to the BCCAO treated group (fig. 2)

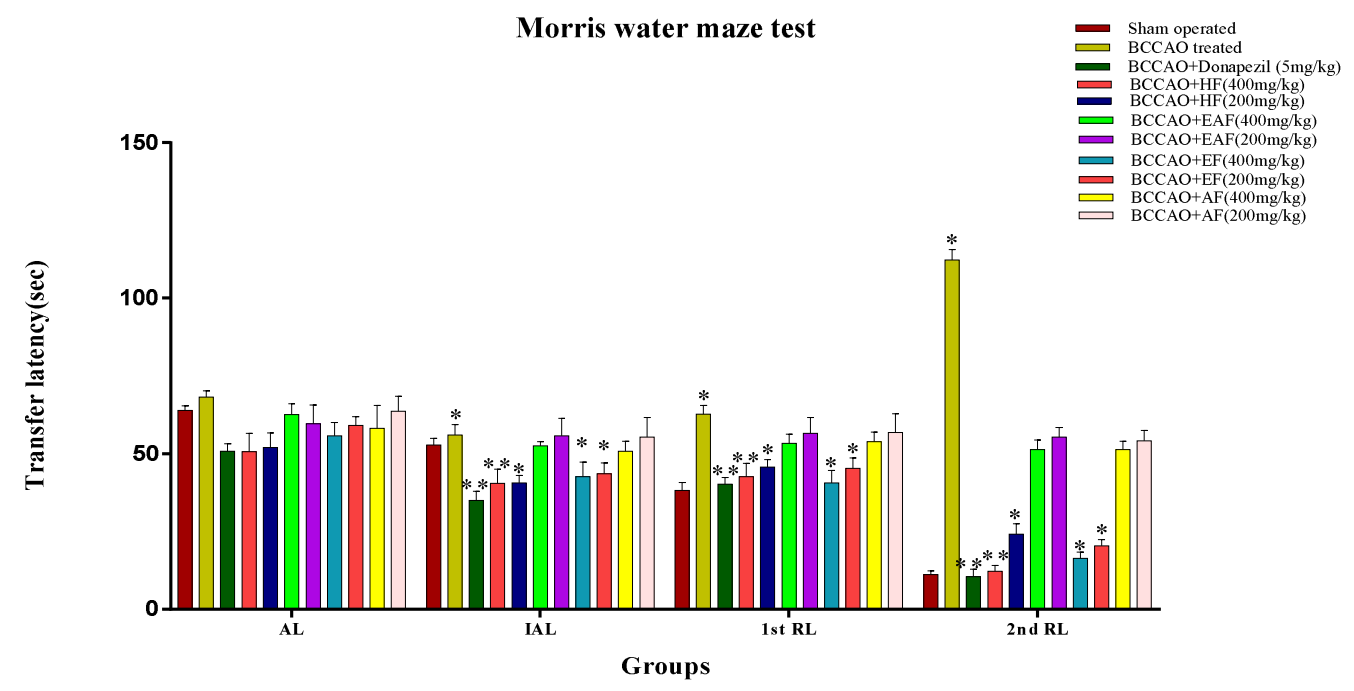

Fig. 1: Effect of Donepezil, CL of HF, EAF, EF and AF successive extracts on spatial navigation task compared to the BCCAO group, values are expressed as mean $\pm \operatorname{SD}(n=6) ;{ }^{*} p<0.05,{ }^{* *} p<0.01$ as compared with corresponding values of BCCAO group. (One way ANOVA followed by dunnett's test)

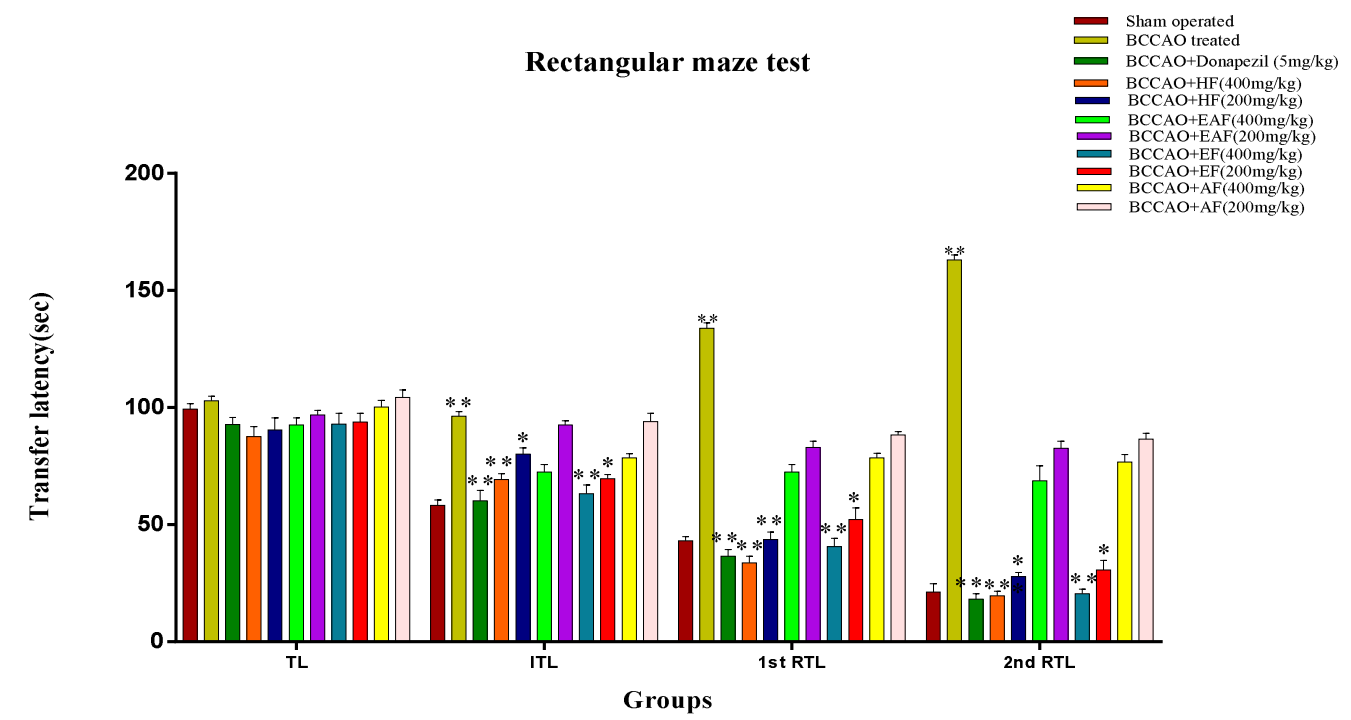

Fig. 2: Effect of Donepezil, CL of HF, EAF, EF and AF successive extracts on memory performance in rectangular maze compared to the BCCAO group, values are expressed as mean $\pm S D(n=6) ;{ }^{*} p<0.05,{ }^{* *} p<0.01$ as compared with corresponding values of $B C C A O$ group. $(0 n e$ way ANOVA followed by dunnett's test)

\section{Effect of CL on locomotor activity}

The mean scores of locomotor activity for each rat were showed significant variation among different groups. The mean scores in sham-operated, donapezil $(5 \mathrm{mg} / \mathrm{kg}, \mathrm{PO})$ and $\mathrm{CL}$ various extracts (HF, EAF, EF and $\mathrm{AF}$ of 400 and $200 \mathrm{mg} / \mathrm{kg}, \mathrm{PO}$ ) rats cause significant increase in locomotor activity compared to BCCAO treated rats on days 13 and 21 as compared to pretraining locomotor activity on day 1 and 7 in concentration-dependent manner. More significant $(\mathrm{P}<0.05$ and $\mathrm{P}<0.01$, respectively) increase in locomotory activity was seen in CL extracts of HF and EF rats, when compared to CL extract of EAF and AF, treated rats (fig. 3).

\section{Antioxidant effect of citrulus lanatus on BCCAO induced rats}

Cerebral ischemia followed by reperfusion caused a significant rise in brain MDA levels and depletion of CAT, DPPH levels in BCCAO treated animals as compared to sham-operated animals. However chronic CL extracts HF, EF (400 and $200 \mathrm{mg} / \mathrm{kg}, \mathrm{PO}$ ) treatment significantly $(\mathrm{P}<0.01)$ attenuated the increase in MDA levels and also caused a significant $(\mathrm{P}<0.01)$ increase in CAT and DPPH levels when compared to the BCCAO treated rats. Whereas there were no significant differences were observed in EAF and AF treated animals (table 2).

Brain acetylcholine levels by citrulus lanatus on BCCAO induced rats

BCCAO followed by reperfusion showed a significant increase in the brain AchE activity as compared to sham-operated rats. However, chronic CL extracts HF, EF (400 and $200 \mathrm{mg} / \mathrm{kg}, \mathrm{PO}$ ) treatment significantly $(\mathrm{P}<0.01)$ attenuated enhanced AchE activity compared to BCCAO treated rats. (table 2) but there were no significant differences were observed in EAF and AF treated animals. 


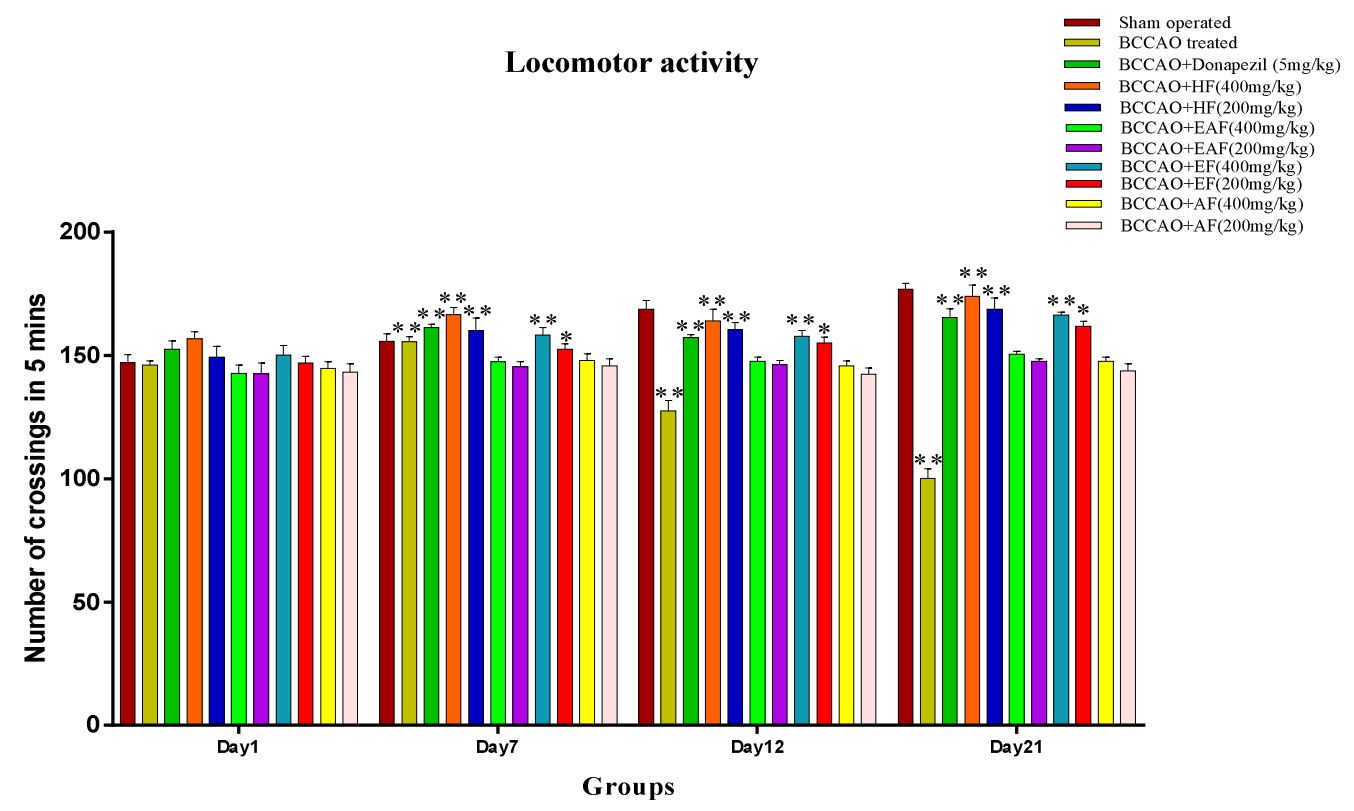

Fig. 3: Effect of donepezil, CL of HF, EAF, EF and HEF successive extracts on locomotor activity compared to the BCCAO group, values are expressed as mean $\pm \mathrm{SD}(\mathrm{n}=6) ;{ }^{*} \mathrm{p}<0.05,{ }^{* *} \mathrm{p}<0.01$ as compared with corresponding values of $\mathrm{BCCAO}$ group. (One way ANOVA followed by dunnett's test)

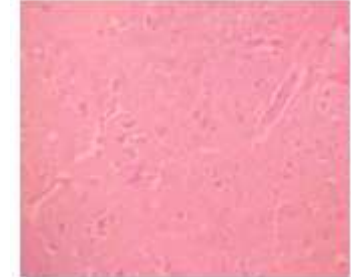

(A)

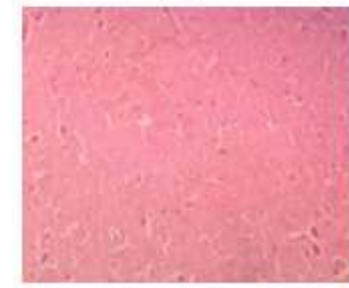

(D)

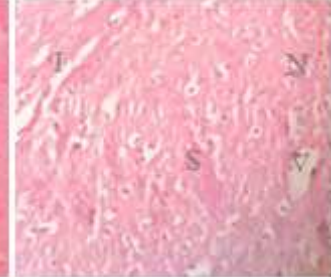

(B)

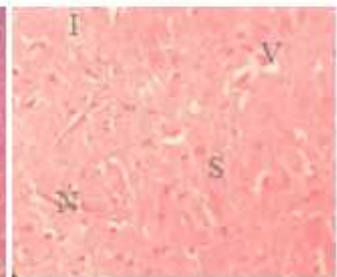

(E)

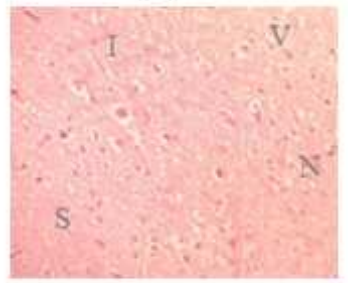

(G)
(C)

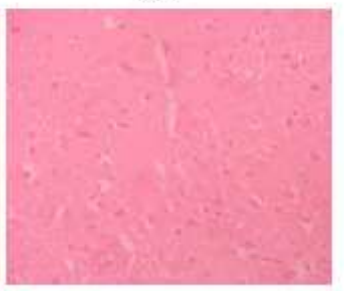

(F)

Fig. 4: Histopathological representative photographs (H and E stain) of hippocampal brain sections, (A) sham operated (B) BCCAO treated (C) Donapezil (D, E, F, G) citrulus lanatus extracts of HF, EAF, EF and AF $400 \mathrm{mg} / \mathrm{kg}$ treated ischemic groups respectively, which were observed under 40X magnification [inflammatory infiltration (I), Necrosis (N), shrinkage (S) vacuolization (V)]

\section{Histopathological results}

From the fig. 4 histopathological study, it was observed that 30 min of BCCAO followed by $7 \mathrm{~d}$ reperfusion produced shrinkage, atrophy and necrosis of neurons along with the vacuolization and inflammatory infiltration in the hippocampal regions of disease control animals when compared with normal control animals. The reactive changes were significantly attenuated in the HF, EF and donapezil pretreated animals as compared to disease control animals. However, no significant changes were observed in the $\mathrm{EAF}$ and AF treated animals when compared to disease control animals. 
Table 2: Effect of donapezil, CL seed HF, EAF, EF and AF successive extracts on BCCAO induced alteration in animals brain MDA, CAT, DPPH and AchE levels

\begin{tabular}{|c|c|c|c|c|}
\hline Treatment (mg/kg) & MDA (nmol/g tissue) & $\begin{array}{l}\text { CAT }\left(\mu \mathrm{mol} \text { of } \mathrm{H}_{2} \mathrm{O}_{2} \mathrm{~min} / \mathrm{mg}\right. \\
\text { tissue })\end{array}$ & $\begin{array}{l}\text { DPPH (Free radical } \\
\text { scavenging \%) }\end{array}$ & $\begin{array}{l}\text { AchE activity } \\
(\mu \mathrm{mol} \mathrm{SH} / \mathrm{g} / \mathrm{min})\end{array}$ \\
\hline Sham operated & $15.26 \pm 1.30$ & $11.2 \pm 0.5$ & $65.31 \pm 1.20$ & $7.92 \pm 1.3$ \\
\hline BCCAO treated & $30.15 \pm 1.56$ & $4.15 \pm 1.2$ & $25.13 \pm 1.20$ & $17.22 \pm 2.4$ \\
\hline Donapezil-5 & $16.59 \pm 3.60^{* * *}$ & $9.11 \pm 1.8^{* * *}$ & $48.9 \pm 2.6^{* * *}$ & $7.24 \pm 4.1^{* * *}$ \\
\hline $\mathrm{HF}-400$ & $17.60 \pm 2.70^{* * *}$ & $8.0 \pm 0.7^{* * *}$ & $45.21 \pm 2.80^{* * *}$ & $7.34 \pm 2.31^{* * *}$ \\
\hline $\mathrm{HF}-200$ & $18.1 \pm 3.1^{* * *}$ & $7.6 \pm 0.5^{* * *}$ & $40.18 \pm 1.30^{* *}$ & $6.9 \pm 1.3^{* * *}$ \\
\hline EAF-400 & $27.6 \pm 4.2$ & $4.1 \pm 1.9$ & $25.12 \pm 4.10$ & $17.6 \pm 1.6$ \\
\hline EAF-200 & $28.1 \pm 5.6$ & $4.6 \pm 1.3$ & $23.21 \pm 3.10$ & $17.89 \pm 2.3$ \\
\hline$E F-400$ & $20.65 \pm 4.20^{* *}$ & $7.6 \pm 1.5^{* * *}$ & $45.31 \pm 2.50^{* *}$ & $11.6 \pm 2.1^{* *}$ \\
\hline EF-200 & $21.1 \pm 3.2^{* *}$ & $6.9 \pm 1.3^{* *}$ & $39.18 \pm 4.10^{*}$ & $13.9 \pm 1.5^{*}$ \\
\hline $\mathrm{AF}-400$ & $29.1 \pm 1.2$ & $4.5 \pm 2.1$ & $24.01 \pm 2.20$ & $17.8 \pm 2.6$ \\
\hline $\mathrm{AF}-200$ & $28.6 \pm 6.6$ & $3.9 \pm 1.6$ & $22.09 \pm 1.30$ & $17.9 \pm 1.3$ \\
\hline
\end{tabular}

Values are expressed as mean \pm SD $(n=6){ }^{*} \mathrm{p}<0.05,{ }^{* *} \mathrm{p}<0.01,{ }^{* * *} \mathrm{p}<0.001$ as compared with corresponding values of disease control group (one way ANOVA followed by dunnett's test).

\section{DISCUSSION}

Cerebral ischemic injury induced by BCCAO induces transient metabolic changes in various brain regions. Reperfusion injury results when cell damage induced by ischemia is heightened by postischemic reperfusion. Restoration of blood flow to an ischemic brain region is associated with the generation of reactive oxygen species with consequent reperfusion injury [24]. BCCAO for 30 min followed by reperfusion was associated with increased generation of reactive oxygen species [25].

The principal finding of the present study is that the cerebral ischemic reperfusion injury was associated with oxidative stress, as evidenced by an increase in brain AchE, MDA levels and depletion of cerebral endogenous antioxidants like CAT, DPPH activities in BCCAO treated rats. Similar observations made earlier by other studies [26, 27]. Increased levels of MDA reflect the membrane damage induced by toxic lipid peroxidation products. The depletion in CAT and DPPH enzymes was observed and taken as a marker of oxidative stress. In present study indicating that the administration of CL extracts prevented the oxidative stress and the biochemical changes associated with cerebral ischemic reperfusion injury. The mechanism of such protection of oral administration of CL extracts may be due to cerebral adaptation, through augmentation of cellular antioxidants such as DPPH and CAT. In cerebral ischemic reperfusion damage, oxidative stress plays a major role in its etiopathogenesis. Protection against oxidative stress through this mechanism may be one of the effective therapeutic approaches.

Oxidative stress is believed to be a central source for the generation of post cerebral ischemic injury. Various experimental models of cerebral ischemic reperfusion injury showed significant neuroprotection when treated with antioxidants [28]. Recent survey has shown that many dietary polyphenolic components derived from plants are more effective antioxidants In vitro than vitamins $\mathrm{E}$ or $\mathrm{C}$, and thus might contribute significantly to the protective effects in vivo [29].

There is extensive evidence which supports the antioxidant activity of CL seed extracts and the potency of anti-oxidant activities depending on the type of extract [30]. Augmentation of endogenous antioxidants by therapeutic substances has recently evoked scientific interest because any such property of a therapeutic agent can be expected to cause a significant improvement in the endogenous defense against oxidative stress. [31] The observed beneficial effects of CL extracts on cerebral ischemic reperfusion injury-induced changes in biochemical parameters may thus be attributed to its various chemical constituents. BCCAO produces marked destruction of hippocampal granule cells, resulting in loss of cholinergic neurons with a significant increase in AchE activity thereby leading to learning and memory deficits.

In the present study, BCCAO treated rats showed significant memory impairment in water maze and rectangular maze tasks which were attenuated by CL treatement. Major findings of this study are that Chronic administration of CL various extracts $\mathrm{HF}, \mathrm{EAF}, \mathrm{EF}$ and $\mathrm{AF}$ of
400 and $200 \mathrm{mg} / \mathrm{kg}$, PO) beginning prior to cerebral ischemia was able to improve the cognitive deficit and attenuated oxidative stress, suggesting that $\mathrm{CL}$ improves cognitive task and has antioxidant like effect. CL extracts of $\mathrm{HF}$ and EF more significantly improved the cognitive functions and ameliorates the BCCAO induced decrease in AchE activity than extracts of EAF and AF when compared to the BCCAO treated animals.

\section{CONCLUSION}

The present study suggests that chronic administration of CL extracts of $\mathrm{HF}$ and EF prevents BCCAO induced cognitive impairment and associated oxidative stress. Thus, the use of CL extracts of $\mathrm{HF}$ and $\mathrm{EF}$ is promising for the treatment of $\mathrm{AD}$ and other neurodegenerative disorders.

\section{ACKNOWLEDGMENT}

The authors would like to thank the Principal and Management of Vaagdevi College of Pharmacy, Warangal for providing the necessary facilities to carry out this research work.

\section{AUTHORS CONTRIBUTIONS}

Mrs. Girija Pashikanti gave a substantial contribution by executing the experimental work in our laboratories, drafted the manuscript and extensively revised to improve the quality of the manuscript. Conception, the design of the study and supervision of the work were done by Dr. Goverdhan Puchchakayala and Dr Makula Ajitha.

\section{CONFLICTS OF INTERESTS}

The authors declare no conflicts of interest

\section{REFERENCES}

1. Rang HP, Dale MM, Ritter JM, Flower RJ. Neurodegenerative diseases. In: Elsevier limited. Rang and Dale's Pharmacology. $6^{\text {th }}$ edition. USA; 2008. p. 514-5.

2. Mcllroy S, Craig D. Neurobiology and genetics of behavioral syndromes of Alzheimer's disease. Curr Alzheimer Res 2004;1:135-42.

3. Poornima Venkat BS, Michael Chopp PhD, Jieli Chen MD. Models and mechanisms of vascular dementia. Exp Neurol 2015;272:97-108.

4. Frank B, Gupta S. A review of antioxidants and Alzheimer's disease. Annals Clin Psychiatry 2005;17:269-86.

5. Kumar A, Naidu PS, Seghal N, Padi SSV. Effect of curcumin on intracerebroventricular colchicine-induced cognitive impairment and oxidative stress in rats. J Med Food 2007;10:486-94.

6. Rajadurai M, Prince PSM. Preventive effect of naringin on lipid peroxides and antioxidants in isoproterenol-induced cardiotoxicity in wistar rats: biochemical and histopathological evidences. Toxicology 2006;228:259-68.

7. Vant Veer P, Jansen MC, Klerk M, Kok FJ. Fruits and vegetables in the prevention of cancer and cardiovascular disease. Public Health Nutr 2000;3:103-7. 
8. Bokov A, Chaudhuri A, Richardson A. The role of oxidative damage and stress in aging. Mech Ageing Dev 2004;125:811-26.

9. Jain S, Jerald EE, Edwin S. Isolation, fractionation and evaluation of the anti-inflammatory properties of Citrullus lanatus Thunb. Asian I Biomed Pharma Sci 2013;3:66-72.

10. Chinmay D, Deshmukh, Anurekha J, Mukul ST. Phytochemical and pharmacological profile of Citrullus lanatus (Thunb): an international quarterly. J Biol Life Sci 2015;3:483-8.

11. Acute Oral Toxicity. Acute oral toxic class method guideline 423 adopted 17.12.2001 OECD, guidelines for the testing of chemicals organisation for economical co-operation and development, Paris; 2000.

12. Kalyani P, Ajith B, Sravanthi A, Goverdhan P. Neuroprotective effect of pyritinol and fluvastatin in cerebral ischemic reperfusion injury and memory dysfunction. Adv Biol Res 2014;8:68-78.

13. Prakash T, Kotresh D, Rama RN. Neuroprotective activity of Wedelia Calendulacea on cerebral ischemia/reperfusion induced oxidative stress in rats. Indian J Pharmacol 2011;43:1-8.

14. Lin $\mathrm{Y}$, Chen $\mathrm{F}$, Zhang J, Wang $\mathrm{T}$, Wei $\mathrm{X}, \mathrm{Wu} \mathrm{J}$, et al. Neuroprotective effect of resveratrol on ischemia/reperfusion injury in rats through TRPC6/CREB pathways. J Mol Neurosci 2013;50:504-13.

15. Frautschy $\mathrm{SA}, \mathrm{Hu} \mathrm{W}$, Kim $\mathrm{P}$. Phenolic anti-inflammatory antioxidant reversal of $A \beta$-induced cognitive deficits and neuropathology. Neurobiol Aging 2001;22:993-1005.

16. Reddy DS, Kulkarni SK. The possible role of nitric oxide in the nootropic and antiamnesic effects of neurosteroids on agingand dizocilpine-induced learning impairment. Brain Res 1998;799:215-29.

17. Goverdhan P, Sravanthi A, Mamatha T. Neuroprotective effects of meloxicam and selegiline in scopolamine-induced cognitive impairment and oxidative stress. Int J Alzheimer's Dis 2012;18. Doi:10.1155/2012/974013

18. Agarwal A, Malini S, Bairy KL, Rao MS. Effect of tinospora cordifolia on learning and memory in normal and memory deficit rats: Indian J Pharmacol 2002;34:339-49.

19. Priyadarshini A, Yeswanth Reddy M, Goverdhan P. Neuroprotective effect of Aegle marmelos leaf extract in scopolamine induced cognitive impairment and oxidative stress in mice. Global J Pharmacol 2016;10:45-53.
20. Wills ED. Mechanisms of lipid peroxide formation in animal tissues. Biochemical J 1966;99:667-76.

21. Luck H. Catalase. In: Bergmeyer HU. Editor. Methods of enzymatic analysis. New York: Academic Press; 1971. p. 88593.

22. Kaur IP, Geetha T. Screening Methods for Antioxidants: a review. Mini Rev Med Chem 2006;48:305-12.

23. Ellman GL, Courtney KD, Andres Jr V, Featherstone RM. A new and rapid colorimetric determination of acetylcholinesterase activity. Biochem Pharmacol 1961;7:88-90.

24. McCord JM. Oxygen derived free radicals in post-ischemic tissue injury. N Engl J Med 1985;312:159-63.

25. Yanpallewar SU, Acharya SB. Nimodipine attenuates biochemical, behavioral and histopathological alterations induced by acute transient and long-term bilateral common carotid occlusion in rats. Pharmacol Res 2004;49:143-50.

26. Sorrenti V, Di Giaxomo C, Renis M, Russo A, La Della C, PerezPolo JR. Lipid peroxidation and survival in rats following cerebral post-ischemic reperfusion: Effect of drugs with different molecular mechanisms. Drugs Exp Clin Res 1994;20:185-9.

27. Nakashima M, Niwa M, Iwai T, Uematsu T. Involvement of free radicals in cerebral vascular reperfusion injury evaluated in a transient focal cerebral ischemia model of rats. Free Radical Biol Med 1999;26:722-9.

28. Sudhir CK, Nagarathna PKM, Sainadh N, Vasanthakumar C. Evaluation of cerebroprotective effect of flavonoid of dalbergia latifolia against cerebral ischemia re-perfusion induced cerebral infarction in rats by BCCAO method: research and reviews. J Pharmacol Toxicol Stud 2013;1:8-14.

29. Catherine RE, Nicholas JM, George P. Antioxidant properties of phenolic compounds. Trends Plant Sci 1997;2:152-9.

30. Habibur Rahman, Manjula $K$, Anoosha $T$, Nagaveni $K$, Eswaraiah M, Dipankar B. In vitro anti-oxidant activity of citrullus lanatus seed extracts: Asian J Pharm Clin Res 2013;6:152-7.

31. Gauthaman KK, Salem MTS, Thanislas PT, Prabhu VV, Krishnamoorthy KK, Devaraj NS, et al. Cardio protective effect of the Hibiscus rosa sinensis flowers in an oxidative stress model of myocardial ischemic reperfusion injury in rats. BMC Comp Alt Med 2006;6:32-40. 